\title{
STATUS OF ORGANIC AGRICULTURE RESEARCH AND DEVELOPMENT PROGRAMS IN THE BICOL REGION, PHILIPPINES
}

\author{
Ma. Teresa B. Lirag ${ }^{1}$, Georgina J. Bordado ${ }^{2}$ \\ ${ }^{I}$ Central Bicol State University of Agriculture, Pili, Camarines Sur, Philippines \\ ${ }^{2}$ Central Bicol State University of Agriculture, Pili, Camarines Sur, Philippines
}

\begin{abstract}
A study was conducted to determine the status of the organic agriculture (OA) research and development ( $R$ and D) programs in Bicol Region, Philippines. Specifically, it aimed to conduct inventory of $\mathrm{R}$ and $\mathrm{D}$ projects on organic agriculture, determine the information needs of $\mathrm{OA}$ stakeholders and identify research gaps and propose strategies to enhance the OA R and D programs. Secondary data was gathered on OA researches undertaken and survey was conducted to 149 stakeholders to know their information needs. Data gathered showed that 46 projects were implemented and most of the researches conducted were on production aspect. Highest percentage (34\%) recorded in terms of information needs of the stakeholders were on demand and supply. Research gaps identified were absence of a whole research chain on organic agriculture for a specific commodity, lack of a research with component on developing a centralized, web-based information system, and inadequate research on policy and governance on OA. Recommendations included the strengthening of research programs with holistic approach, development of a web-based OA information system, conduct of research on governance, policy processes on OA and strengthening of financial support from government and private institutions and intensification of information dissemination campaign on organic agriculture.
\end{abstract}

Keywords: organic agriculture, organic farming, organic growers, research and development

\section{INTRODUCTION}

The Philippine agriculture contributes 17 percent to the country's gross domestic product, employing 33 percent of the country's labor force. Agricultural commodities such as palay and corn production for 2015 were lower by $4.31 \%$ and $3.24 \%$, respectively, compared to the 2014 levels. The decrements were attributed to the lower area harvested and yield brought by insufficient water supply, dry spell/drought, and adverse effects of typhoons (Philippine Statistics Authority, 2016).Likewise, In a report made by Cabigas and Morala (2011), it stated that this sector accounts for more than half or an estimated 66 percent of the country's poorest. The deteriorating condition of the environment has contributed to increasing vulnerability of the agriculture sector particularly to extreme weather events. Pre-dominance of chemical-intensive farming has contributed to at least 33 percent of the country's greenhouse gas emissions.

In the Bicol region, intensive use of chemical fertilizers has caused high acidity in paddy fields. Farmers had to increase the amount of chemical fertilizer in order to secure certain yield. Thus the inputs of chemical fertilizers have increased over time causing further acidity of soil and soil erosion (Ara, 2002).In the rice industry, conventional method of farming requires chemical fertilizers, pesticides and herbicides. Though touted for its high yields, this production system is believed to enhance soil degradation, pollution, chemical residues in food and loss in biodiversity (Mendoza, 2002). It also intensifies the farm household's actual and physiological burden on high-cash capital expenses 
(Mendoza 2003). With the multitude of adverse impacts of conventional agriculture and the pressing problems facing the agriculture sector, it is essential to push for the implementation of alternative method such as organic agriculture.

Organic crops are one of the most important needs for Filipino farmers. They provide the needed nutritive value as well as food security not only to farmers but to consumers as well. Scientific studies also indicate the need for more organically grown crops in the diet to help suppress heart disease, cancer and other diseases.

Hence, the signing of Republic Act No. 10068 known as the Philippine Organic Agriculture Act, on June 16, 2012 was considered by many as a landmark legislation which provided for the development and promotion of $\mathrm{OA}$ in the Philippines. It is a culmination of long years of development efforts mostly by non-government, community based organizations and private groups pushing for agriculture sector reforms around ecologically sustainable, environment friendly and safer production systems, availability of safer and more nutritious staples and food and increased farm productivity and income opportunities for Filipino farmers (NOAP, 2012).

The attributes of organic agriculture is indeed, favorable to the community and environment. Because of this, there had been a growing concern to strengthen organic agriculture. For instance, market share of organic and partially organic rice accounts for 0.9 percent of the rice from irrigated land. But the number of adopters has been increasing dramatically (Ara, 2002). Large scale production for organic crops is now being encouraged during these times when farmers as well as consumers are becoming conscious of the adverse effects of using pesticides and fertilizers in farms.

This growing interest on OA is well supported by some government agencies (Briones, 2011). In 1997, the Philippines Council for Agriculture, Forestry, Fisheries and Natural Resources Research and Development (PCARRD) sponsored a national consultation workshop on OA where speakers from organic producers in the private sector and members of International Federation of Organic Agriculture
Movements (IFOAM) were invited to interact with government researchers. PCARRD is just one of the many organizations which had shown interest and generated voluminous information on OA which need to be gathered and made available systematically to OA stakeholders.

While organic farming is definitely creating waves in the agriculture sector, there are setbacks which had been initially identified in its implementation. In a research study conducted by ElsWynen, several problems were noted that cause problems for the advancement of research in organic agriculture. One of them is absence of networks by researchers in organic agriculture. In addition to this, other concerns and issues were the present structure of research funding; the different requirements in organic agriculture leading to rather expensive research; lack of a united front by the organic sector; relative lack of good researchers and inadequate structure to foster them (by good supervision of potential researchers and peer review); and lack of policies which encourage research in organic agriculture directly or indirectly.

These setbacks should not become the reason for researchers to discontinue and be disenchanted on OA. Bicol Region, Philippines which is the locale of this study has a great potential for organic agriculture. The region's total agricultural area is891, 955 hectares, and $5 \%$ of this is targeted to be utilized for organic agriculture. Report revealed that seventy-four percent $(74 \%)$ of organic rice production and $44 \%$ of the country's over-all production of other organic crops come from Bicol region (Department of Agriculture, 2015).

The platform for OA implementation is indeed, very promising. However, a dearth of information on consumer/market demand, input resources, commodity pricing, R \& D interventions and other relevant information on organic products in particular and organic agriculture in general has been identified. Access to these information is limited and more often than not, unavailable and incomplete. Likewise, there is a need for a network of information and stakeholders on organic agriculture do not know where to start to obtain it.Cognizant of this situation, there is a need to make information especially on R \& 
D initiatives on organic agriculture readily available, hence, this study.

\section{OBJECTIVES}

This study aims to:

1. conduct inventory of $\mathrm{R} \& \mathrm{D}$ projects on organic agriculture

2. determine the information needs of stakeholders in organic agriculture

3. identify research gaps and propose strategies to enhance the $\mathrm{R} \& \mathrm{D}$ program on organic agriculture in the Bicol region

\section{METHODOLOGY}

A survey was conducted to OA stakeholders such as farmers, organic growers and local government officials to determine their information needs on organic agriculture. A survey-questionnaire was prepared for this purpose and questions on the communication media preferred by farmers and other stakeholders in disseminating OA information were likewise included.

An inventory of $\mathrm{R} \& \mathrm{D}$ initiatives and projects on organic agriculture was also conducted. Secondary data was gathered from educational institutions, agencies, non-government organizations (NGOs) and private organizations (POs) on researches, initiatives and interventions undertaken related to organic agriculture.

\section{RESULTS AND DISCUSSION}

A survey was conducted to gather data needs and information from organic agriculture stakeholders. The place of study is in Bicol Region, Philippines (Figure 1).Organic agriculture is pushed by various sectors in this region and it is spearheaded by the Department of Agriculture (DA). In fact, the DA eestablished within the vast agricultural property that the Pecuaria Development Cooperative Inc. (PDCI) is tending in Barangay Lapigna, Bula, Camarines Sur the one-hectare demo farm has been planted to organic and aromatic rice varieties called JM2 and Basmati (Philippine News Agency, 2012).

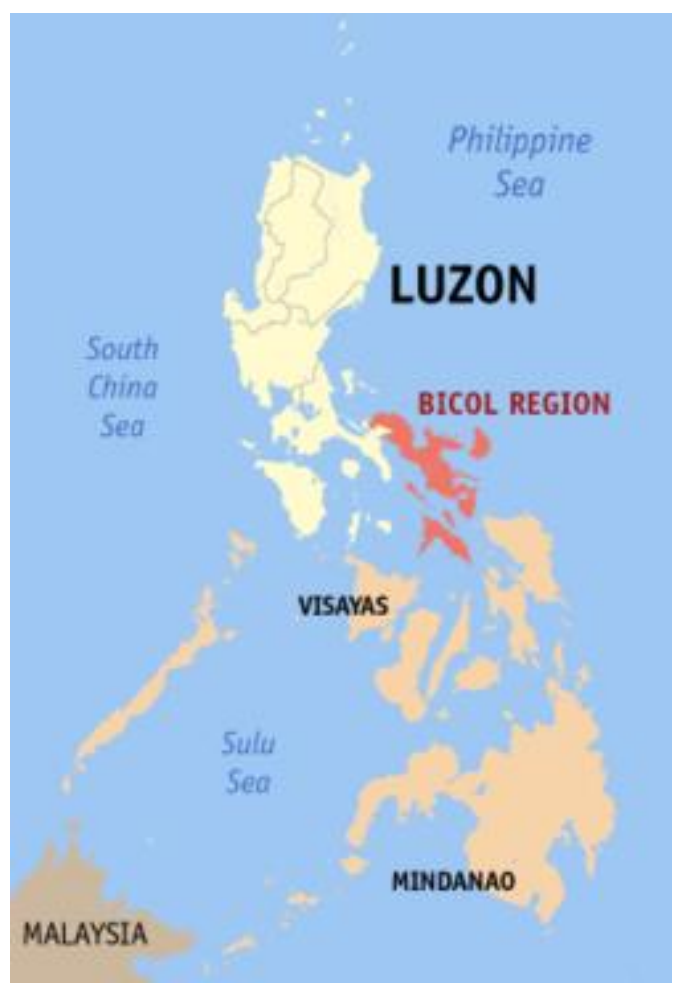

Figure 1.Map showing the Location of the Project Site, Bicol Region, Philippines

Table 1shows the respondent's profile from the four provinces in the Bicol Region. Sixty (60) percent and $40 \%$ of the respondents are males and females, respectively. Majority of the respondents (30\%) belong to age 51-60 years old, $25 \%$ with age range $31-40$ years old, $20 \%$ and $19 \%$ belong to ages $61-70$ and 41-50 years old, respectively. In terms of occupation, about half of them $(60 \%)$ are farmers and the remaining respondents are either government employees or involved in other sources of livelihood like fishing, carpentry and domestic work. 
Table1. Demographic Profile of Respondents

\begin{tabular}{|c|c|c|}
\hline & Number & $\%$ \\
\hline \multicolumn{3}{|l|}{ A. Sex } \\
\hline Male & 89 & 60 \\
\hline Female & 60 & 40 \\
\hline Total & 149 & 100 \\
\hline \multicolumn{3}{|l|}{ b. Age } \\
\hline 71 - above & 2 & 1 \\
\hline $61-70$ & 30 & 20 \\
\hline 51-60 & 45 & 30 \\
\hline $41-50$ & 28 & 19 \\
\hline $31-40$ & 37 & 25 \\
\hline below 30 & 7 & 5 \\
\hline Total & 149 & 100 \\
\hline \multicolumn{3}{|l|}{$\begin{array}{l}\text { c. } \\
\text { Occupation }\end{array}$} \\
\hline Farmers & 89 & 60 \\
\hline $\begin{array}{l}\text { LGU/Govt. } \\
\text { Employee }\end{array}$ & 51 & 34 \\
\hline Others & 9 & 6 \\
\hline Total & 149 & 100 \\
\hline
\end{tabular}

Fifty three percent of the respondents come from the province of Camarines Sur and the rest come from Camarines Norte, Albay and Masbate (Table 2). These respondents are farmers and community residents who are involved either directly or indirectly in organic farming activities. Likewise, results revealed that the highest percentage (34\%) recorded in terms of information needs of the stakeholders was on demand and supply(Table 3). Respondents revealed that they are willing to adopt organic farming but the problem is, they do not have the information where lies the great demand for organic produce in the region. Market for organic products is not yet stable and therefore, there is not sufficient guarantee that farmers' produce can be disposed within a particular period of time. It is therefore, essential to carefully consider product stabilization in order for farmers to secure their source of income. This is further supported by the report of Ara (2002) that product stabilization with enough technical support and farmers' education and appropriate marketing system for organic rice are necessary for the development of organic farming in the Philippines. Likewise, markets, not production, increasingly drive agricultural development. Value addition \& product differentiation is becoming increasingly 
Table 2. Distribution of Respondents by Province

\begin{tabular}{ccc}
\hline Province & Number & Percent \\
\hline Camarines Sur & 79 & 53 \\
\hline Camarines Norte & 25 & 17 \\
\hline Albay & 24 & 16 \\
\hline Masbate & 21 & 14 \\
\hline Total & 149 & 100 \\
\hline
\end{tabular}

important to ensure increase in income, reducing malnutrition/poverty and for competing in the global market. This is further supported by a study made by Bhatta, et. al in 2009 wherein it revealed that before beginning cultivation of organic crops, their marketability and that too at a premium over the traditional and modern produce has to be assured. Inability to obtain a premium price, at least during theperiod required to achieve the productivity levels of the conventional crop is a setback in Nepal. High prices of these products remain a major deterrent for consumers.

Focus should not only be given to marketing of products but policy implementation should be carefully considered as well. In a study made by Tamayo, Castro and Lim (2013), it emphasized the interconnectedness of the various stakeholders of organic agriculture which includes farmers themselves, the retailers/marketers/merchandisers, and the finally consumers. According to them, all

Table 3. Information Needs of Stakeholders in Organic Agriculture

\begin{tabular}{lcc}
\hline Category/Aspect & Total & $\%$ \\
\hline A. Production & 37 & 25 \\
\hline B. Marketing & 46 & 31 \\
\hline C. Demand and Supply & 51 & 34 \\
\hline D. Profile of stakeholders & 15 & 10 \\
\hline TOTAL & 149 & 100 \\
\hline
\end{tabular}

these sectors must be given due attention in the crafting of the law for organic agriculture. Institutionalizing organic farming is making organic 
Table 4. Preferred Communication Media on Organic Agriculture

\begin{tabular}{lcc}
\hline \multicolumn{1}{c}{ Communication Media } & Total & $\%$ \\
\hline A. Online/Internet & 33 & 15 \\
\hline B. Broadcast (Television/Radio) & 75 & 34 \\
\hline $\begin{array}{l}\text { C. Print (Newspapers, } \\
\text { Magazines/Flyers/Brochures) }\end{array}$ & 36 & 17 \\
\hline D. Fora/Conferences/Symposia & 62 & 28 \\
\hline E. Others (Cellphone) & 14 & 6 \\
\hline TOTAL & 220 & 100 \\
\hline
\end{tabular}

Table 5. Organic Agriculture R \& D Projects, Bicol Region, Philippines

\begin{tabular}{lll}
\hline Systems Flow & Number & $\%$ \\
\hline A. Production & 25 & 54 \\
\hline B. Marketing & & \\
\hline Demand and Supply & 4 & 9 \\
\hline Promotion & 5 & 11 \\
\hline Profile of OA stakeholders & 4 & 9 \\
\hline C. Processing & 8 & 17 \\
\hline \multicolumn{1}{c}{ TOTAL } & 46 & 100 \\
\hline
\end{tabular}

In other countries, the role of media in enticing farmers to turn to organic agriculture is also very crucial. For instance, production of training manuals and making them accessible to farmers is a welcome step towards their appreciation of organic farming. Aleading research institute in Europe named the Switzerland's Research Institute of Organic Agriculture (FiBL) prepared an African Organic Agriculture Training Manual to improve access of African farmers to markets, especially to the organic market. Organizations involved in training in organic and sustainable agriculture are invited to use the new training materials and contribute to their further improvement.Likewise, Hossain (2012) also noted in their study in Bangladesh that media (both electronictelevision and radio and print-newspapers) play important roles in increasing awareness of farmers and consumers. Similarly, in China, most organic food production is managed by smallholder farmer organizations which are not well organized and managed. Most of the farmers do not understand the essence of organic production. They only know that no chemical inputs are allowed in organic production, the economic aspects attract them to cooperate with the companies (Qiao, 2011).Given this scenario, the role of media in making the farmers appreciate better organic farming is likewise, very important. Also, there is a popular perception in the world about "good farming" that is extremely emotionalized (the feelings of the topic and the aspects shown) and romanticized and the media and advertisements play a major role (Rahmann et.al, 2009).

In this study, a total of $46 \mathrm{R} \& \mathrm{D}$ projects were identified. Table 5 shows the priority list of OA R \& $\mathrm{D}$ projects conducted based on commodity system flow. Most of the researches conducted were on production aspect which included studies on cropping system, crop improvement, soil, pest management, weed control, productivity performance of organic crops grown such as rice, sweet sorghum, lettuce, stevia. Funding of projects generally comes from the 
Department of Agriculture and DA - Bureau of Agricultural Research and academic institutions.

In a similar fashion, the development of organic farming in Korea focused on projects that aim at gaining economic benefits from producing organic products with high value-added tax, limit to the maximum the use of chemical complex including chemical fertilizer and agrochemicals to protect and improve the agricultural ecology and sustainably develop the agricultural production (Development of Organic Farming in the DPR Korea, 2008). Furthermore, in a project report prepared by Elm Farm research Centre in 2003, cropping systems \& crops have the overwhelming majority of projects in the United Kingdom, funding and intensity of research. Livestock systems \& livestock follow this. These two production orientated topics are followed by information \& dissemination and soil \&nutrient cycling. The other topics receive considerably less resources, with environment, sustainability \& conservation having relatively few expensive and long running projects, resulting in much lower research intensity.

Based on the above data gathered, additional researchable areas and research gaps were identified:

1.A whole research chain on organic agriculture which will include inputs, production, marketing, processing and support mechanism for OA.

2. While there are numerous researches which are location-specific (i.e. municipality or province), these information are difficult to access by other stakeholders. A research with a component on developing a centralized, web-based information system is essential.

3.A research on policy and governance on OA assessing the ability of the policy-makers and local government officials to implement them at the local and regional level.

\section{CONCLUSION AND RECOMMENDATIONS}

There is voluminous information available regarding organic agriculture research and development initiatives locally and globally. At the regional level, most of the researches focused on the production aspect of organic crops. On the other hand, the information needs of OA stakeholders which should be given priority attention are on marketing aspect especially on the demand and supply side of OA products. Likewise, the preferred communication media for disseminating this information is through conduct of fora and symposia and through broadcast media, either by radio or television. Research gaps identified include a whole research chain on OA, development of a centralized web-based information system and a research on effective implementation of policy and governance of OA programs at the local and regional level.

Based on the results of the study, the following strategies are recommended:

1.Intensify $\mathrm{R}$ \& $\mathrm{D}$ initiatives which will extend through the whole research chain putting more focus along the areas of marketing and processing of organic products and developing new markets as well as market network at the local, regional and national level.

2.Conduct research on governance, policy processes as it relates to the implementation of organic agriculture program.

3.Continue the conduct of inventory survey and mapping of relevant information on organic agriculture which is crucial in the data content buildup of a centralized organic agriculture database/information system at the regional and national level

4.Establish an on-farm research in order to generate more information for organic farmers

5. Develop a user-friendly and easy-to-use website and information system for marketing organic products and accessing information on organic farming and agriculture.

6.Establish and maintain a database of accredited organic farm growers to include both the local and national growers, sellers and producers who are into organic farming and development.

7.Strengthen financial support from institutions such as the Department of Agriculture (DA) and Department of Agriculture-Bureau of Agricultural 
Research (DA-BAR) for the conduct of researches on market and processing of organic products.

8.Intensify information dissemination campaign and awareness on organic agriculture using broadcast and print media and the conduct of fora/symposia that will serve as a good venue for information exchange among OA stakeholders.

\section{ACKNOWLEDGEMENT}

The authors are grateful to the Central Bicol State University of Agriculture headed by then University President Atty. Marito T. Bernales, Ph.D. for allowing them to conduct this project. Likewise, they are grateful to Intervida Foundation, Philippines and the Department of Agriculture Region 5, Philippines for providing them the budget for this research.

\section{REFERENCES}

ARA, S. 2002. Environmental Evaluation of Organic Rice: A Case Study in the Philippines. M.S. Thesis. Department of Economics Kobe University Rokkadai-cho, Nada-ku Kobe, Hyogo, Japan.

Bhatta, G., Doppler, W., Bahadur, K. 2009. Potentials of Organic Agriculture in Nepal. The Journal of Agriculture and Environment Vol:10.

Briones, A. National Study: Philippines. University of the Philippines at Los Banos, Laguna, Philippines.Date of Access: December, 2014. http://www.unescap.org/rural/doc/OA/Philippines.

Cabigas and Morala. 2011. "Enhancing Labeling, Standards and Certification for Sustainable, Organic and Ecological Agriculture in the Philippines", La Liga Policy Institute.

FiBL. Excellence For Sustainability, African Organic Agriculture Training Manual: Knowledge Shall Help Make Farmers More Fit for Business. 2012. Switzerland's Research Institute of Organic Agriculture (FiBL)

Galvez, J. 2015. DA bats for competitive, safe farm products. Date of Access. May 2016. http://www.manilatimes.net/da-bats-for-competitivesafe-farm-products/169134/

Hawkes, C.et. al. August 2012. Current and Planned Research on Agriculture for Improved Nutrition: A Mapping and Gap Analysis. A Report for DFIP.

Hossain,S., Sugimoto, H, Ueno, H. and Huque, M. 2007.Adoption of Organic Rice for Sustainable Development in Bangladesh. Ehime University, Matsuyama, Japan. ISSN 1177-4258.Journal of Organic Systems - Vol.2 No.2.
Ior - Elm Farm Research Centre.A review of UK research and development for organic food and farming. Project Code OF0338. 2003. Department for Environment, Food and Rural Affairs - Final Project Report.

Mendoza, T. 2002. "Impact Analysis of Organic Farming in Rice Agroecosystems In the Philippines". First RDA/ARNOA International Conference, RDA and Dankook University of Korea.

Mendoza, T. 2003. "Upscaling the Adoption of Ecologically Sound Agriculture in the Philippines. Date of Access. December, 2014. http://www.rosneath.com.au/ipc6/ch06/mendoza/inde x.html

Middendorf, G. July 2006. Challenges and Information Needs for Organic Production in Kansas. Research Report.

National Organic Agriculture Program (211-2016). January 9, 2012.

Philippine News Agency. 2012. Department of Agriculture puts up demo farm to revitalize organic agriculture in Bicol. Date of access. December, 2014. http://interaksyon.com/article/50659/da-puts-updemo-farm-to-revitalize-organic-agriculture-in-bicol

Philippine Statistics Authority.2016. Date of Access. May 2016. http://agstat.psa.gov.ph/?ids=downloads_view\&id=90 8

Qiao, Y. 2011. Asia: Country Report China. Organic Agriculture Development in China. The World of Organic Agriculture. Statistics and Emerging Trends.

Rahmann, G., Oppermann, R. Paulsen, H. and Weibmann, F. 2009. Good, but not good enough? Research and development needs in Organic Farming. Agriculture and Forestry Research. (59):294029.

Tamayo, A., Castro, R., Lim, M. 2013. Government, Business and Market of Organic Products in Davao City Philippines. International Review of Management and Business Research Vol. 2 Issue 3. The Development of Organic Farming in the DPR Korea (2005)

Wynen, E. Research on Biological Farming Methods in Europe Perspectives, Status and Requirements. Date of Access December 2014. http://www.fao.org/DOCREP/006/AD244E/ad244e0 5.htm 